\title{
Comparison of Two Cone-Beam Computed Tomography Systems Regarding Linear Measurement Accuracy for Implant Sites in the Mandible: An In-Vitro Study
}

\section{Amir Eskandarloo', Abbas Shokri' ${ }^{1}$, Aydin Salehi Milani², Mohammad Reza Jamalpoor ${ }^{3}$, Karim Ghazikhanlou-Sani, ${ }^{4, *}$}

${ }^{I}$ Associate Professor, Department of Oral and Maxillofacial Radiology, School of Dentistry, Hamadan University of Medical Sciences, Hamadan, Iran

${ }^{2}$ Oral and Maxillofacial Radiology Specialist

${ }^{3}$ Associate Professor, Department of Oral and Maxillofacial Surgery, School of Dentistry, Hamadan University of Medical Sciences, Hamadan, Iran

${ }^{4}$ Assistant Professor, Department of Medical Physics, Paramedical School, Hamadan University of Medical Sciences, Hamadan, Iran

* Corresponding Author: Karim Ghazikhanlou-Sani, Department of Medical Physics, Paramedical School, Hamadan University of Medical Sciences, Hamadan,Iran.Email: ghazi@umsha.ac.ir

Received: 13.10 .2017

Accepted: 15.01 .2018

How to Cite this Article:

Eskandarloo A, Shokri A, Salehi

Milani A, Jamalpoor MR,

Ghazikhanlou-Sani K. Compa-

rison of Two Cone-Beam

Computed Tomography Systems

Regarding Linear Measurement

Accuracy for Implant Sites in the

Mandible: An In-Vitro Study.

Avicenna J Clin Med. 2018; 24(4):

345-351. DOI: $10.21859 / \mathrm{ajcm}$ 24.4.345.

\section{Abstract}

Background and Objective: There are critical areas in the mandible that should be considered during implant placement such as inferior alveolar canal, mental foramen, and the root of the adjacent tooth. Two-dimensional images obtained from periapical, panoramic, and conventional tomography are considered in the evaluation of implant placement and bone quality. Cone-beam computed tomography (CBCT) is a new imaging technique, which is superior to other methods from different aspects. Thus, we aimed to compare the accuracy of two different CBCT systems (i.e., Promax 3D and Newtom 3G) in measuring the anatomic distances in the mandible.

Materials and Methods: In this experimental study, six dry mandibles were used for measuring the width and height of mandible in six areas. Also, caliper was used as the gold standard and the distances were marked by barium sulfate as a radiopaque material. Then, the mandibles were scanned with the two CBCT systems, and the distances were measured by two observers (oral and maxillofacial radiologists) under homogenous conditions by using their respective software. The obtained results were evaluated by multivariate ANOVA and compared with the gold standard.

Results: The accuracy of both CBCT systems (in all the three FOVs) was close to that of collies in measuring the height of mandible. The accuracy of Promax 3D was closer to collies in evaluating bacco-lingual width, and it was more accurate than Newtom $3 \mathrm{G}$ (in all the three FOVs; $\mathrm{P}<0.001$ ). Thus, the accuracy of Promax system is close to the gold standard in the evaluation of the mandible height and bacco-lingual width.

Conclusion: The results of this study showed that Promax 3D and Newtom $3 \mathrm{G}$ techniques (in all the three FOVs) have millimeter precision and are capable of measuring the lengths and widths needed to establish the treatment plan.

Keywords: Cone-beam Computed Tomography, Linear Accuracy, Measurement 


\section{بررسى مقايسهاى دو سيستم Cone Beam CT به لحاظ دقت اندازهَيرى خطى In Vitro محلهاى قراردهى ايميلنت در منديبل بهصورت}

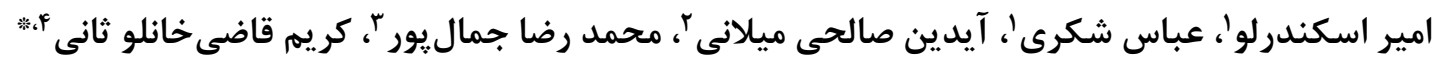
' دانشيار، گروه راديولوزى دهان، فك و صورت، دانشكده دندان يزشكى دانشكاه علوم يزشكى همدان، همدان، ايران

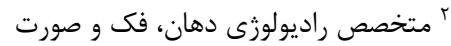

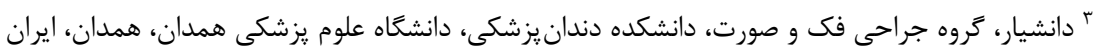

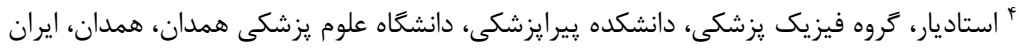
* نويسنده مسئول: كريم قاضى خانلو ثانى، گروه فيزيك يزشكى، دانشكده يِرايزشكى، دانشكاه علوم يزشكى همدان، همدان، ايران. ايميل: ghazi@umsha.ac.ir

\begin{tabular}{|c|c|}
\hline 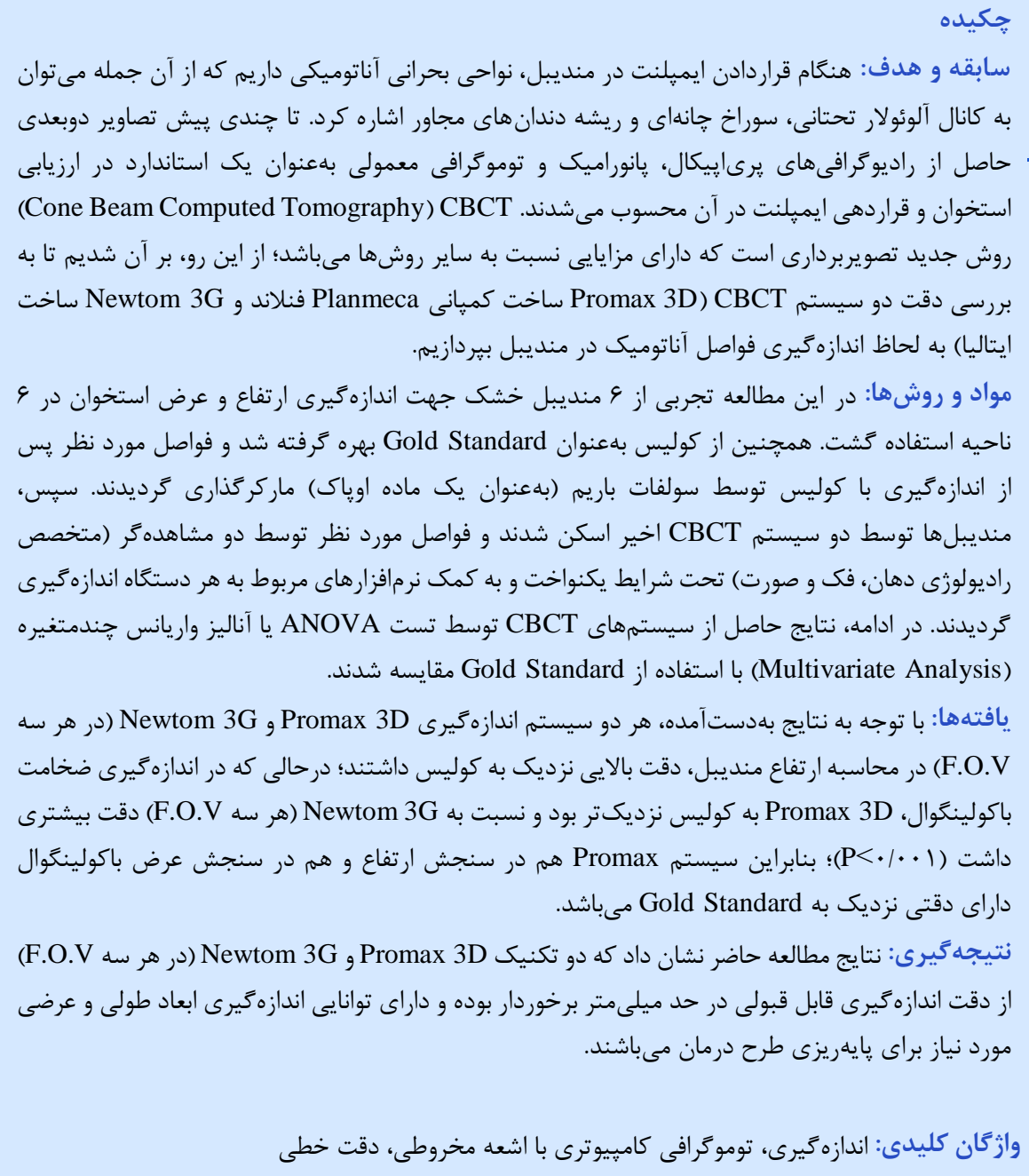 & 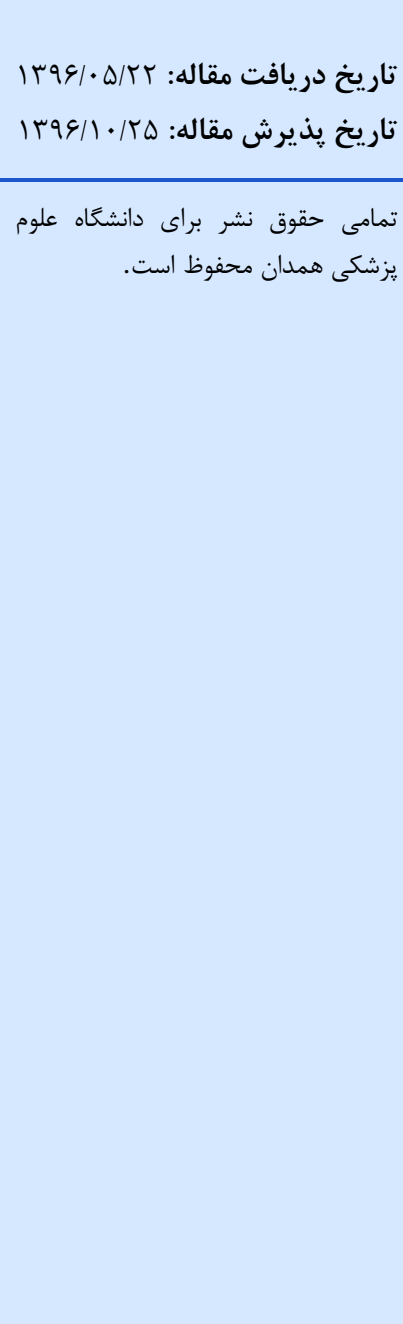 \\
\hline
\end{tabular}

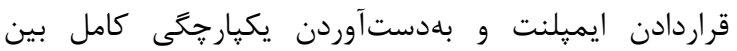

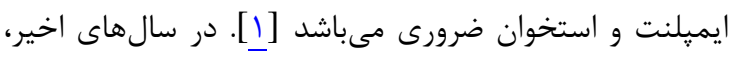

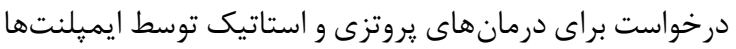

با به روى كار آمدن ايميلنتهاى تيتانيومى اندواسئوس،

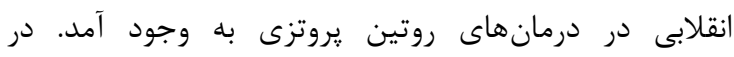

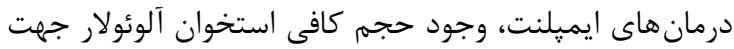


مى تواند رزولوشن را كاهش دهد و دوز بالاترى را به بيمار تحميل

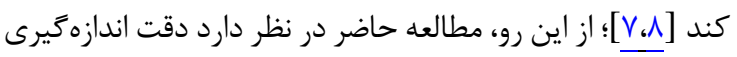

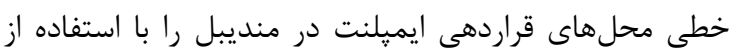

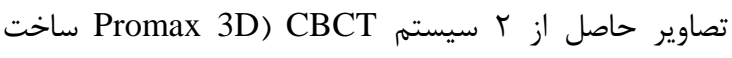
كميانى Planmeca فنلاند و Newtom 3G ساخت ايتاليا) كه داراى Field of View متفاوت و دتكتورهاى با سايز و جنس

$$
\text { مختلف هستند، بررسى نمايد. }
$$

\section{مواد و روشها}

در اين مطالعه تجربى بهمنظور بررسى دقت اندازهيرى

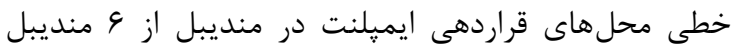

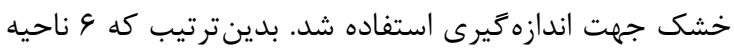

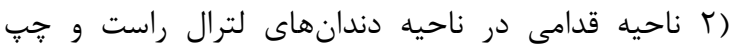

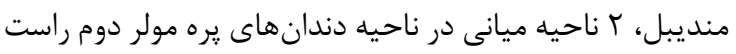

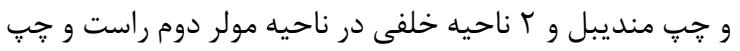

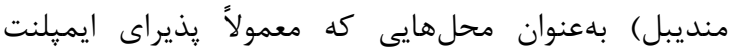

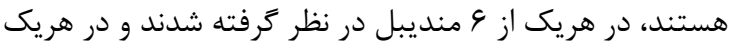

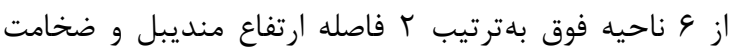

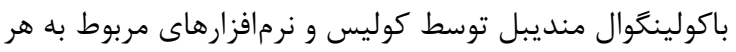
دستخاه اندازهيرى كردين. اندازهيرى هاى كوليس ديجيتال بهعنوان استاندارد طلايى

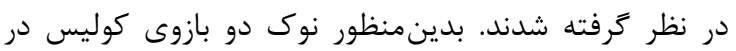

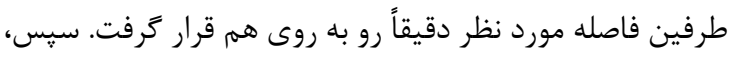

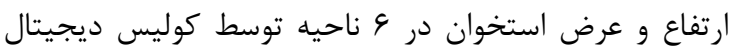

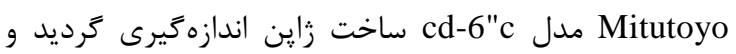

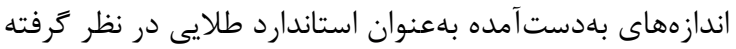

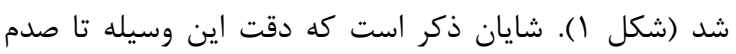
ميلى متر مىباشد؛ اما با توجه به اينكه سيستم

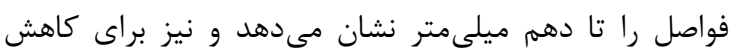

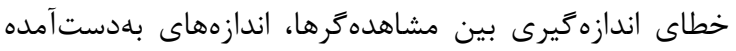

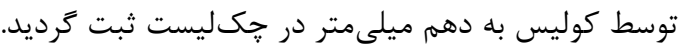

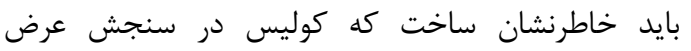

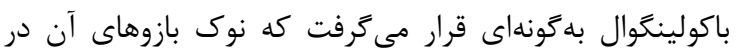

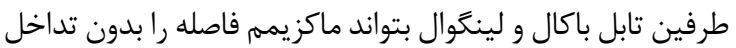

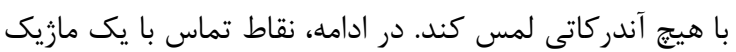

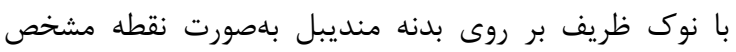

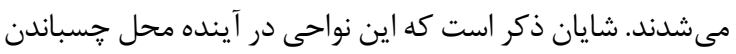
Marker g Spacer جهت سنجش ارتفاع منديبل، مارزين باكالى ساكت دندان

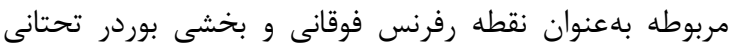

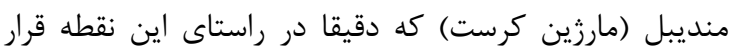
داشت بهعنوان نقطه رفرنس تحتانى در نظر كرانته

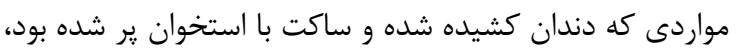

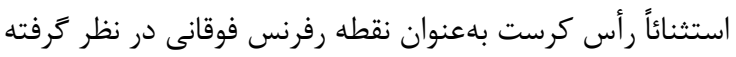

رو به افزايش نهاده است. همانطور كه مى دانيم، نواحى بحرانى آنى

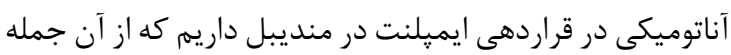

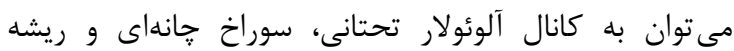

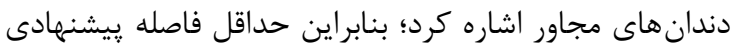

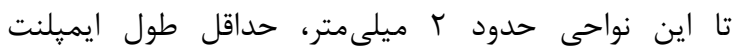

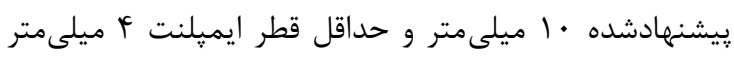

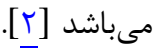

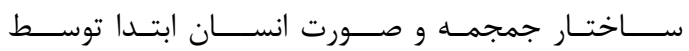

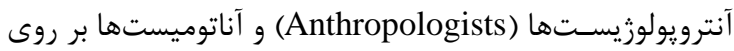

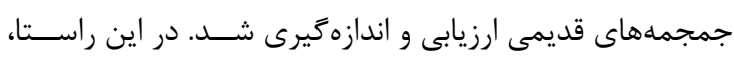

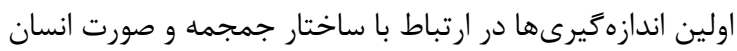

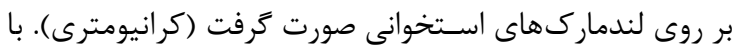

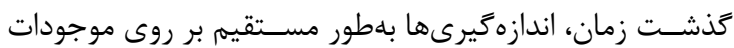

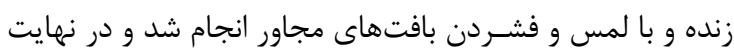

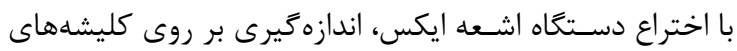

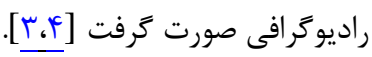

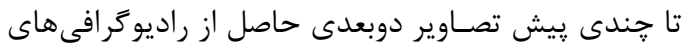

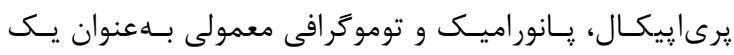

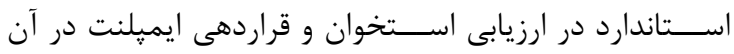

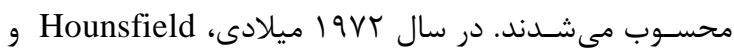
Computed Tomography) CT بـا معرفى Cormack

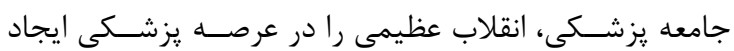

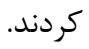
دسته يرتو ايكس در CT بلهورت Fan Shaped از زواياى

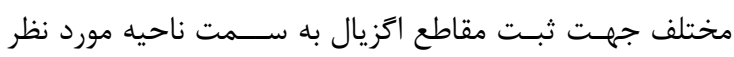

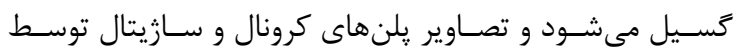

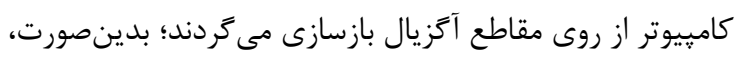

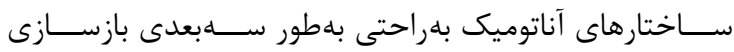

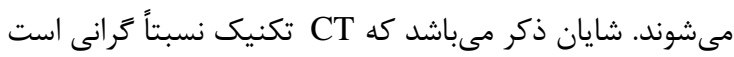

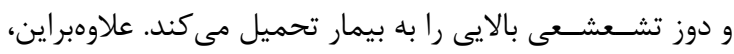

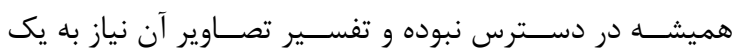
راديولوزيست مجرب دارد. ماند تصوربرد جديد تصويربردارى است كه داراى مزايايى مانند تصويربردارى آسان، دقت بالاى تصاوير، كاهش تصدي آرتيفكت،

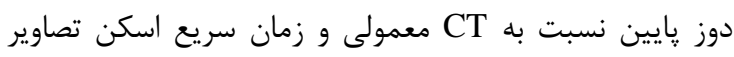

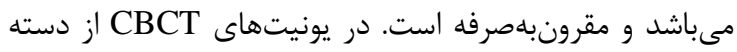

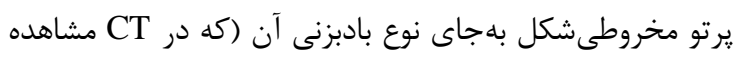

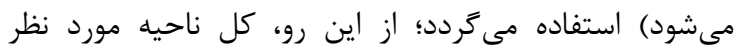
Cone Shaped توسط اين دسته يرتو

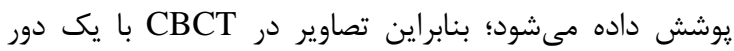

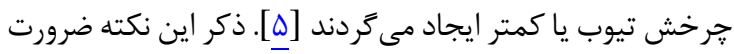

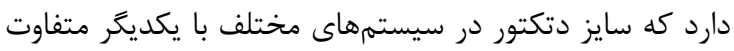

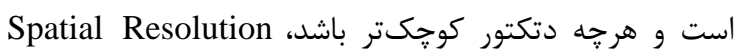

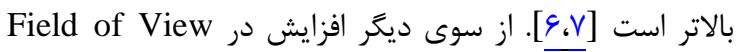




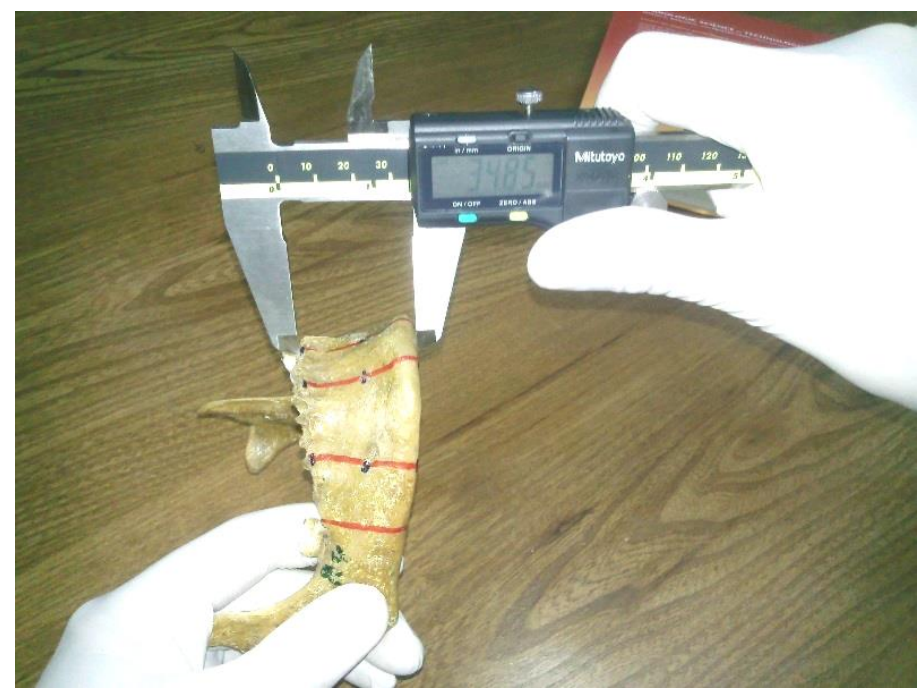

شكل ا: اندازهيرى با كوليس جهت تعيين استاندارد طلايى

كورتكس منديبل كشت و از جابهجايى و كندهشدن آنها طى تصوير بردارى جلو كيرى نمود.

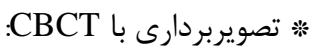

در اين مطالعه از دو دستخاه Promax 3D CBCT ساخت برداه كميانى Planmeca كشور فنلاند و دستخاه

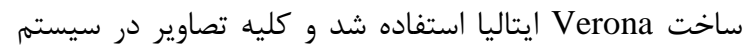
mAs در Planmeca

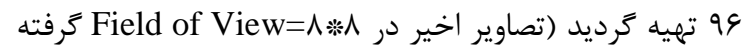

شدند).

در دستخاه Newtom 3G تصاوير توسط سه تصند).

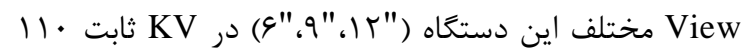

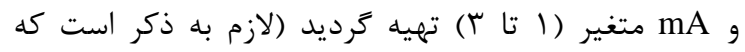
سيستم Newtom 3G داراى برنامه هوشمند Smart Beam

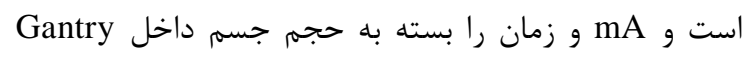
تغيير داده و تنظيم مى نمايد؛ در حالى كه

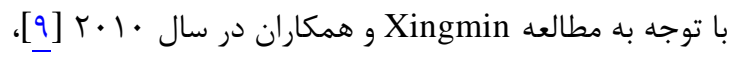

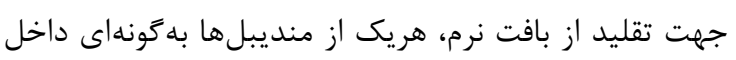

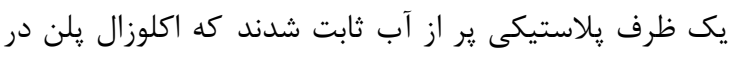

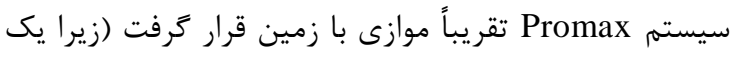

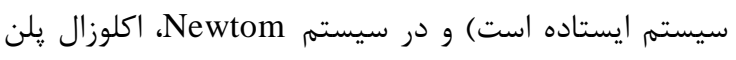
تقريباً عمود بر زمين تنظيمم شد (زيرا يك اديت سيستم سوياين مىباشد).

علاوهبراين، بلمنظور اندازه ميرى ضخامت باكولينگُوال و ارتفاع

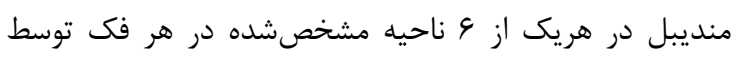

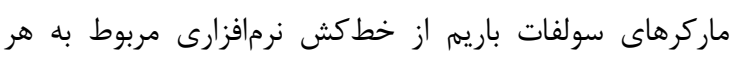

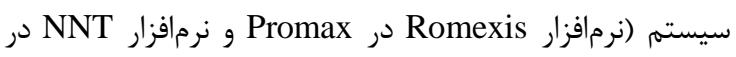
إستفاده شد. لازم به ذكر مىباشد كه اندازمخيرى (Newtom اخير پِ از تهيه مقطع كراس سكشنال در ناحيه ماركرها

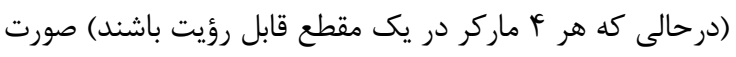

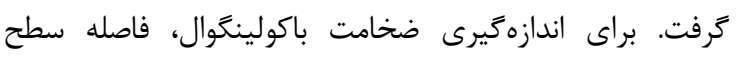

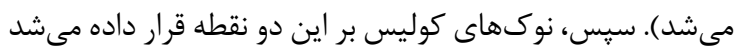

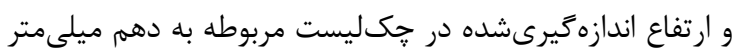
وارد مى گشت. در اين يزوهش بر خلاف ساير مطالعات كه اكثراً

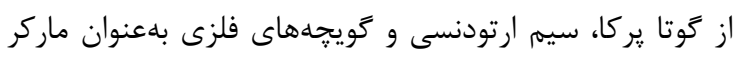

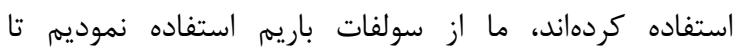

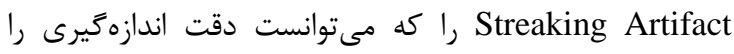
كاهش دهد به حداقل برسانيم. در اين ارتباط، ذكر اين نكته

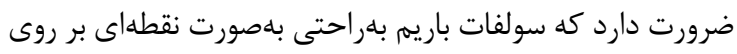
هر سطحى مى جسبد. تماس مستقيم سولفات باريم با سطح منديبل مي توتواند حد

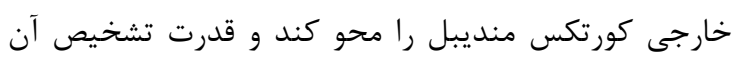

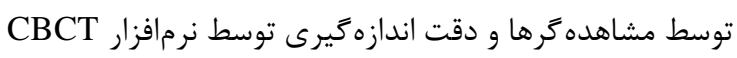

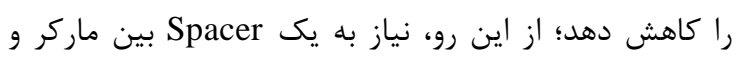

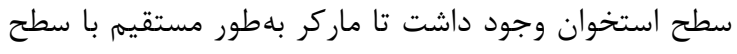

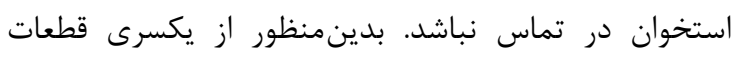

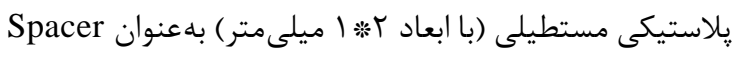
استفاده شد. Spacer ها توسط جسب قطرهاى Super Glue به محل هاى از ييش مشخصشده توسط مازيك در تابل باكال،

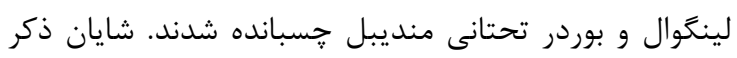

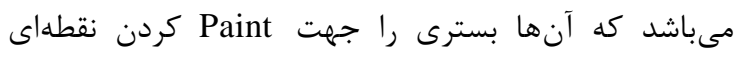

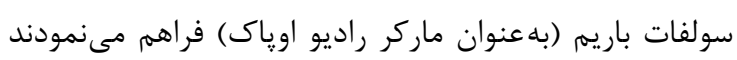

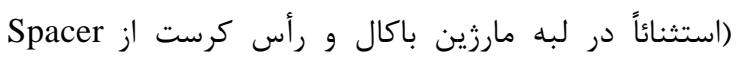

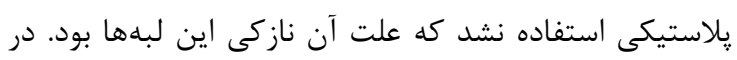

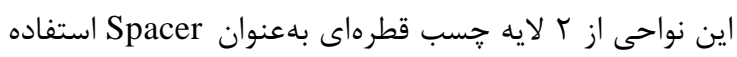

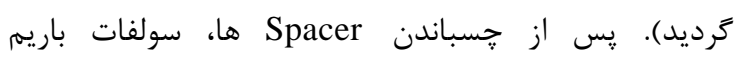
مخلوطشده با آب توسط يك برنيشر ظريف بهصورت نقطهاى

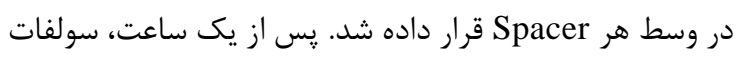

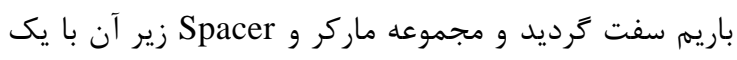

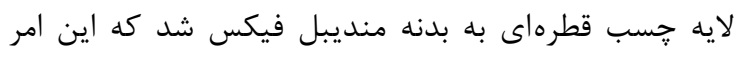
منجر به جسبيدن محكم مجموعه ماركر و و Spacer به لايه 
از سوى ديگر، با توجه به نتايج بهدستآمده از تست آمارى

ANOVA

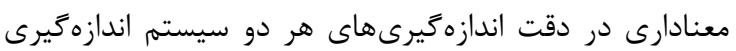
Newtom 3G و در هر سه Promax 3D ارتفاع منديبل با اندازهيرىهاى كوليس وجود نداشت

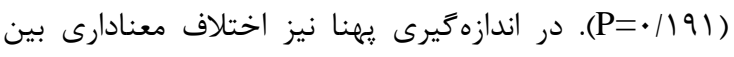
Promax 3D

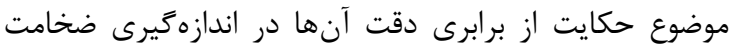

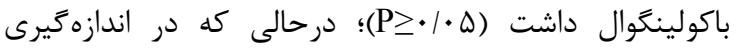

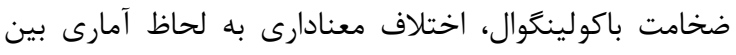

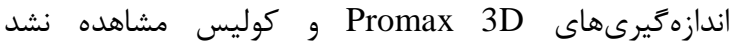
. $(\mathrm{P} \leq \cdot / \bullet 1)$

در مقايسه صورتكرفته بين Newtom 3G (هر سه (F.O.V

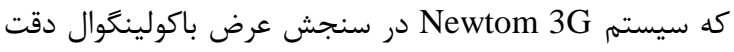

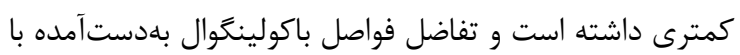

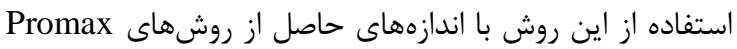
3D

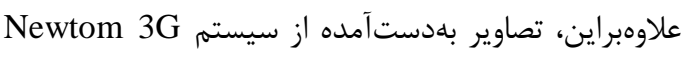

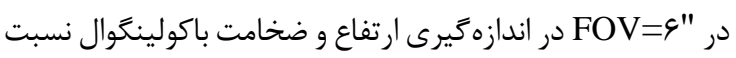
به "FOV=9 و "FOV=أF در همين دستكاه دقيقتر است كه اين دقت از نظر آمارى معنادار نمى باشد.

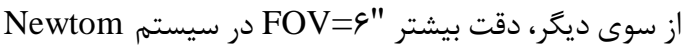

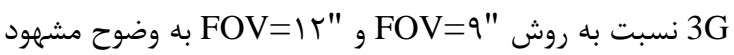

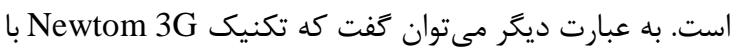

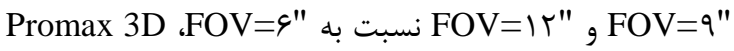
و كوليس داراى بيشبرآوردى (Over Estimation) مىباشد.

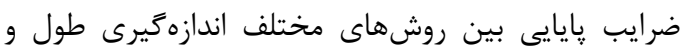
عرض با Gold Standard در جدول ب ارائه شدهاند.
كورتكس خارجى باكال تا سطح خارجى كورتكس لينكَوال در محلهاى مشخصشده توسط ماركرهاى باكال و و لينگوال اندازه مجيرى گرديد. ارتفاع منديبل نيز در حد فاصد ماصل مارزين باكالى

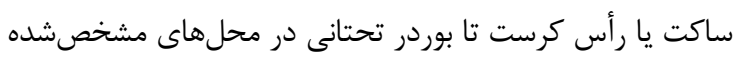

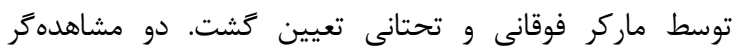

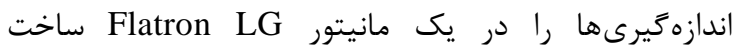
كشور كره با Screen Resolution=1440×900 Pixel تانجام دادند. بدينمنظور آنها در يك Color Depth=32 Bit اتاق تاريك از فاصله r T اينجى بهطور مستقيم به مانيتور

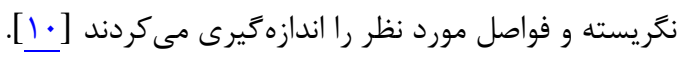

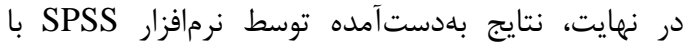

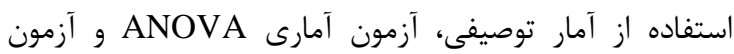
تكميلى Tukey مورد تجزيه و تحليل قرار گرفتند.

\section{بافته ها}

پايايى بين دو مشاهدهر شركت كننده در اين مطالعه در

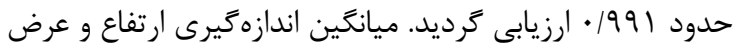
باكولينگوال در سيستمهاى Promax 3D

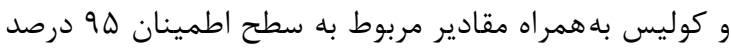

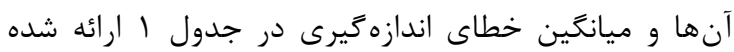

با توجه به نتايج بهدستآمده از اين مطالعه، دقت بالاى

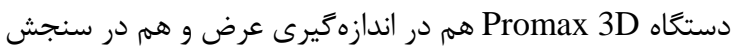

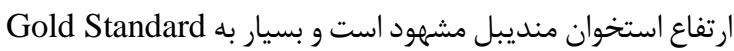
نزديك مىباشد. دستخاه Newtom 3G نيز در هر سه

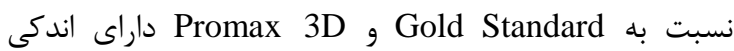
بزرخنمايى است كه در حد دهم ميلىمتر بوده و باز هم كمتر از

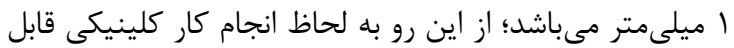
اطمينان است.

جدول ا: ميانگين فواصل اندازهيرىشده به ميلىمتر براى هر روش سنجش

\begin{tabular}{|c|c|c|c|c|c|c|}
\hline 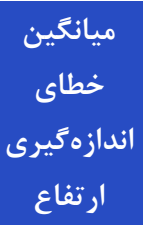 & 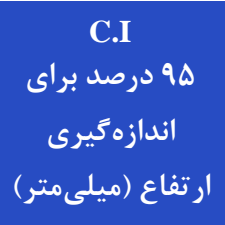 & 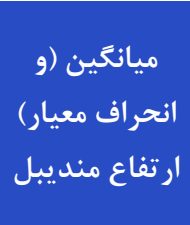 & ميانتين خطاى اندازهيرى عرض & 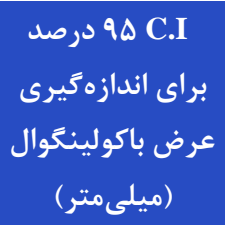 & 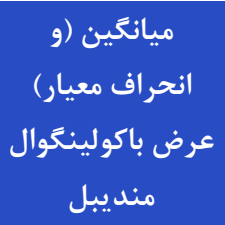 & نحوه سنجش \\
\hline 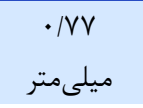 & TF/Q৭-rN/.। & $\begin{array}{l}r G / \mathcal{E V} \\
(\mathcal{F} / A V)\end{array}$ & ^ז/ • ميلى متر & ৭/६६-1./Vq & $\begin{array}{l}1 \cdot / T F \\
(1 / T V)\end{array}$ & كوليس \\
\hline ميلى متر & TQ/T-YN/TT & $\begin{array}{l}r q / 4 q \\
(4 / 94)\end{array}$ & ץ • • ميلى متر & $9 / 94-1 \cdot 19$ & $\begin{array}{l}1 \cdot / T r \\
(1 / V T)\end{array}$ & Promax 3D \\
\hline ميلىمتر & $T \Delta / T I-T A / T V$ & $\begin{array}{l}r G / V I \\
(E / G T)\end{array}$ & سז/• ميلىمتر & $1 \cdot / \cdot r-1 \cdot / 9 r$ & $\begin{array}{l}1 \cdot / F Y \\
(1 / F A)\end{array}$ & $\begin{array}{r}\text { Newtom 3G } \\
(\text { FOV=६") }\end{array}$ \\
\hline ميلى متر & $r \Delta / r-r \Lambda / T I$ & $\begin{array}{l}r G / V \Delta \\
(Y / V)\end{array}$ & س / • ميلى متر & $9 / 9 \vee-1 \cdot / 91$ & $\begin{array}{l}1 \cdot / \& V \\
(1 / \Psi \wedge)\end{array}$ & $\begin{array}{r}\text { Newtom 3G } \\
(\text { FOV=q") }\end{array}$ \\
\hline | ميلىمتر & $T F / A \Lambda-T N / \cdot G$ & $\begin{array}{l}r G / V I \\
(F / G T)\end{array}$ & ז / • ميلىمتر & ৭/৭४-।./A V & $\begin{array}{l}1 \cdot / F F \\
(1 / F T)\end{array}$ & $\begin{array}{l}\text { Newtom 3G } \\
\left(\mathrm{FOV}=I \Gamma^{\prime \prime}\right)\end{array}$ \\
\hline
\end{tabular}


جدول r: ضرايب يايايى بين روش هاى مختلف اندازهخيرى ارتفاع و عرض با Gold Standard

\begin{tabular}{|c|c|c|c|c|c|c|c|}
\hline \multicolumn{2}{|c|}{$\begin{array}{l}\text { Newtom 3G } \\
(\text { FOV=IY") }\end{array}$} & \multicolumn{2}{|c|}{$\begin{array}{l}\text { Newtom 3G } \\
\left(\mathrm{FOV}=q^{\prime \prime}\right)\end{array}$} & \multicolumn{2}{|c|}{$\begin{array}{c}\text { Newtom 3G } \\
\left(\mathrm{FOV}=q^{\prime \prime}\right)\end{array}$} & \multicolumn{2}{|c|}{ Promax 3D } \\
\hline ارتفاع & عرض & ارتفاع & عرض & ار ارتفاع & عرض & ار ارتفاع & عرض \\
\hline$\cdot / \wedge \vee \Delta$ & $\cdot / 911$ & $\cdot \mid \Lambda Q F$ & $\cdot / 911$ & 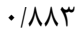 & - /9V9 & - /А१४ & $\cdot / 919$ \\
\hline
\end{tabular}

اين KVP بسيار بالا و NAs يايين در Newtom 3G با وجود

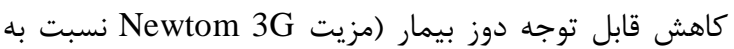
Promax 3D

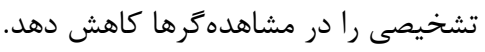

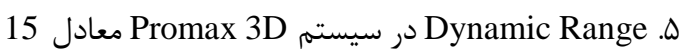
12 Bit مewtom 3G معادل New است درحالى كه در سيستم Bit

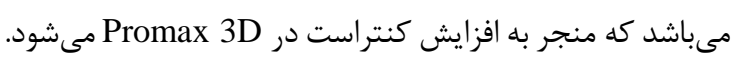

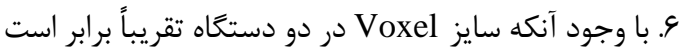

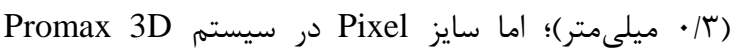

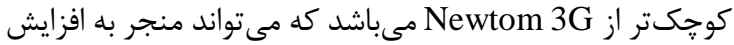
Spatial Resolution

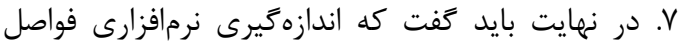
كوجى (مانند عرض باكولينكوال) نسبت به فواصل بزرى (مانند فاصله لبه كرست تا كورتكس تحتانى منديبل) براى مشاهدهر ماهر

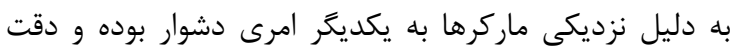

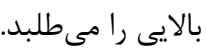
در انتها بايد خاطرنشان ساخت از آنجايى كه اندازهكيرىهاى ما تنها بر ابعاد استخوان منديبل متمركز بوده است، مشاهده

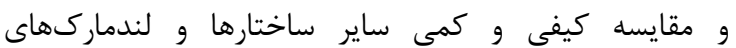
كرانيوفاسيال نظير شاخصهاى ارتودنسى و يا وضعيت كنديل هائا و ميزان ناهنجارىهاى آنها و ضايعات فكى بههمراه مقايسه انواع

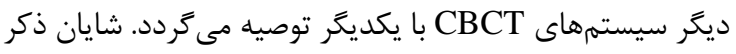

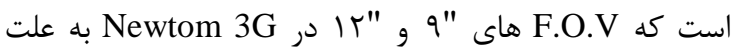

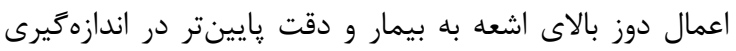

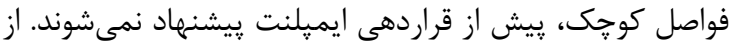

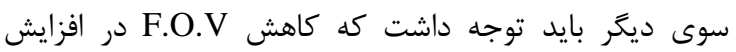
Spatial Resolution مؤثر است؛ اما افزايش دوز ناشى از اين كاهش F.O.V مى

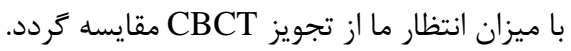

\section{نتيجه تيرى}

نتايج مطالعه حاضر نشان داد كه دو تكنيك Promax 3D و (در هر سه Fewtom 3G

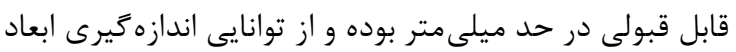

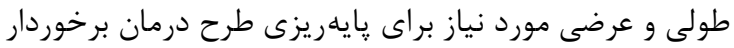

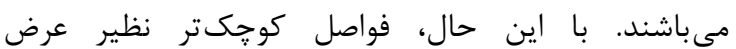
باكو لينكوال منديبل با دقت بالاترى توسط بأند

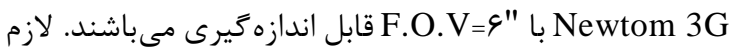

با توجه به نتايج بهدستآمده از اين مطالعه، دقت بالاى

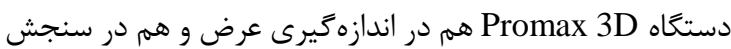
ارتفاع استخوان منديبل مشهود است و بسيار به

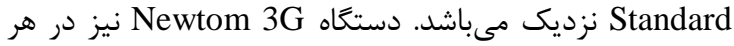

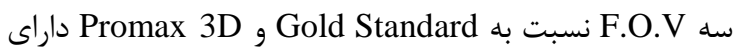
اندكى بزركنمايى است كه در حد دهم ميلىمتر بوده و باز هم

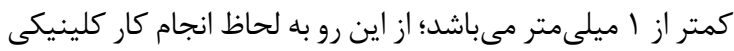

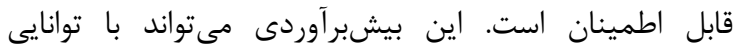

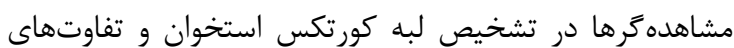
سختافزارى و نرمافزارى بين دو دستخاه توجيه گرددد.

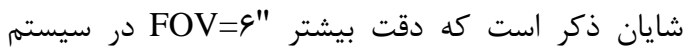
مewtom 3G

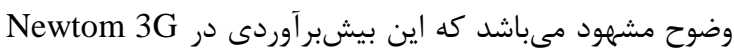
را مىتوان با عوامل زير مرتبط دانست:

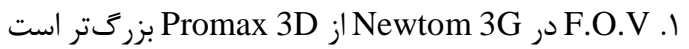

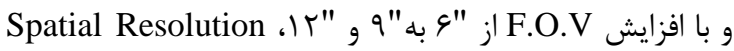
بهوطور مرتب كاسته شده و متعاقباً قدرت تشخيص لبه كورتكس بـ استخوان توسط مشاهدهر ها كاهش مئ يابد. r. يوزيشندهى منديبلها در دو سيستم و Promax 3D متفاوت است (در Newtom 3G بيمار درحالى دهن دئي كه קانه وى به سمت بالا است، بلصورت سوياين داخل Santry

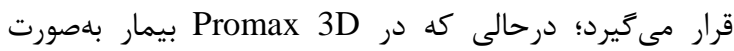

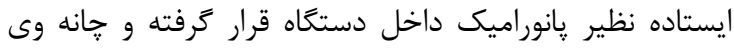

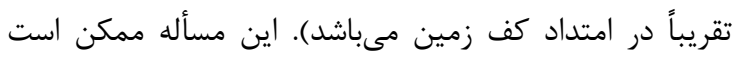
تغييراتى حتى اندك را در نحوه اكسيوزر و دريافت تصاوير ايجاد كند كه نياز به بررسى بيشتر در مطالعات آينده دارد.

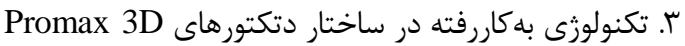
جديدتر بوده و از نوع AFP) Amorph Silicon Flat Panel

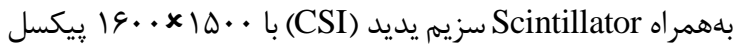
Spatial Resolution مىباشد كه منجر به افزايش قابل توجنه

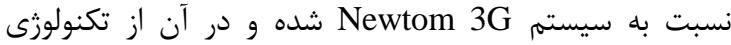

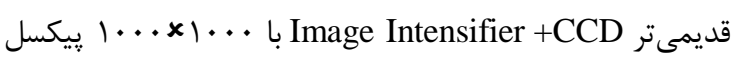
استفاده شده است؛ از اين رو تشخيص لبه كورتكس در دستخاه راحتتر و دقيقتر صورت مى يذيرد. Promax 3D

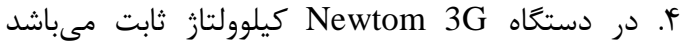

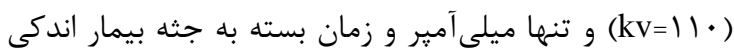

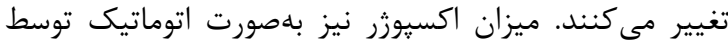
خود دستغاه تنظيم مى گردد (Smart Beam Technology). 


\section{تشكر و قلفرداذى}

اين مقاله برگرفته از ياياننامه دوره تخصصى راديولوزى

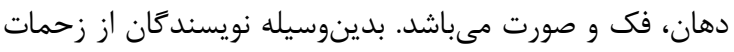

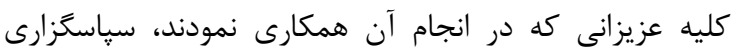
مىنمايند. در ضمن نتايج اين مطالعه با منافع نويسندگان در تعارض نيست.

\section{REFERENCES}

1. van der Zel JF. Implant planning and placement using optical scanning and cone beam CT technology. J Prosthodont. 2008;17(6):476-81. PMID: 18482361 DOI: $10.1111 / \mathrm{j} .1532-$ 849X.2008.00322.X

2. Nickenig HJ, Wichmann M, Hamel J, Schlegel KA, Eitner S. Evaluation of the difference in accuracy between implant placement by virtual planning data and surgical guied templates versus the conventional free-hand method-a combined in vivo -in vitro techniques using cone beam CT (part II). J Craniomaxillofac Surg. 2009;38(7):488-93. PMID: 19939691 DOI: 10.1016/j.jcms.2009.10.023

3. Rubin RM. Making sense of cephalometrics. Angle Orthod. 1997;67(2):83-5. PMID: 9107370 DOI: 10.1043/00033219(1997)067<0083:MSOC>2.3.CO;2

4. Periago DR, Scarfe WC, Moshiri M, Scheet JP, Silver AM, Ferman AG. Linear accuracy and reliability of cone beam CT derived 3-dimensional images constructed using an orthodontic volumetric rendering program. Angle Orthod. 2008;78(3):387-95. PMID: 18416632 DOI: 10.2319/ 122106-52.1

5. Scarfe WC, Farman AG. What is cone-beam CT and how does it work? Dent Clin N Am. 2008;52(4):707-30. PMID: 18805225 DOI: 10.1016/j.cden.2008.05.005

6. Stavropoulos A, Wenzel A. Accuracy of cone beam dental

$$
\begin{aligned}
& \text { به ذكر است كه سيستم Promax 3D جهرت اندازهخيرى } \\
& \text { فواصل خيلى كوجگ تر (نظير تحليل شديد ريج آلوئول) نسبت } \\
& \text { به Newtom 3G با "F.O.V=9 دقيقتر بوده و بسته به طرح } \\
& \text { درمان مورد نظر مى تواند كاراتر باشد. با اين حال در كارگزارى }
\end{aligned}
$$

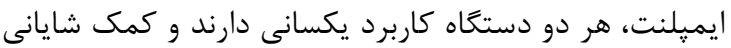

$$
\begin{aligned}
& \text { به جراح مىنمايند. }
\end{aligned}
$$

CT, intraoral digital and conventional film radiography for detection of periapical lesions. An ex vivo study in pig jaws. Clin Oral Investig. 2007;11(1):101-6. PMID: 17048029 DOI: 10.1007/s00784-006-0078-8

7. Alqerban A, Jacobs R, Souza PC, Willems G. In-vitro comparison of two cone beam systems and panoramic imaging for detecting simulated canine impaction-induced external root resorption in maxillary lateral incisor. $A m J$ Orthod Dentofacial Orthop. 2009;136(6):764.e1-11. PMID: 19962592 DOI: 10.1016/j.ajodo.2009.03.036

8. Ludlow JB, Davies-Ludlow LE, Brooks SL, Howerton WB. Dosimetery of $3 \mathrm{CBCT}$ devices for oral and maxillofacial radiology: CB Mercuray, NewTom 3G and i-CAT. Dentomaxillofac Radiol. 2006;35(4):219-26. PMID: 16798915 DOI: $10.1259 / \mathrm{dmfr} / 14340323$

9. $\mathrm{Qu} \mathrm{X1,} \mathrm{Li} \mathrm{G,} \mathrm{Zhang} \mathrm{Z,} \mathrm{Ma} \mathrm{X.} \mathrm{Detection} \mathrm{accuracy} \mathrm{of} \mathrm{in} \mathrm{vitro}$ approximal caries by cone beam CT images. Eur J Radiol. 2011;79(2):e24-7. PMID: 20185260 DOI: 10.1016/j. ejrad.2009.05.063

10. Kamburoglu K, Klsuz E, Kurt H. Accuracy of CBCT measurement of human skull. $J$ Digit Imaging. 2011;24(5):787-93. PMID: 20857166 DOI: $10.1007 / \mathrm{s} 10278$ $\underline{010-9339-9}$ 